\title{
Assessment Practices in Mathematics: Local to Global Contexts
}

\author{
Basanta Raj Lamichhane ${ }^{1}$
}

\begin{abstract}
The main purpose of this paper is to explore the present mathematics assessment practices in local and global contexts. For this, I decisively review educational policies, practices, curricular documents and contemporary researches. In doing so, I select the Finland, China, USA, as they have stood in the significant positions in an international comparative study such as TIMSS, PISA and Nepal. It reveals that the assessment practices in mathematics are not an isolated phenomenon that have been executed by an external authority at the end of the academic sessions to quantify the individual attributes relating to mathematical performances. It is largely embedded in educational activities from the very beginning and simultaneously works throughout the programme for enriching mathematical outcomes and performances of students. I capture two major trends of assessment practices of these countries; post-positivist approaches of assessment and integral approaches of assessment. The post/positivist perspective incorporates summative evaluation techniques and assessment of learning whereas integral perspectives concentrate on assessment for learning as having broad goals of reconstructing, reframing and transforming the entire programs. These trends of assessment practice largely blend with philosophy of mathematics education. The comparing and contrasting views of assessment practices would be helpful for the policy makers, educators, mathematicians and other related personnel for critically re-evaluate their respective assessment practices and thus encourage to transform the deep-rooted conventional assessment practice that is one of the major hindrance to sanction the mathematics education within the positivistic paradigm.
\end{abstract}

Key words: Mathematics assessment, post/positivist perspective, integral perspective, assessment of learning, assessment for learning, assessment as learning.

\section{Emergence of Research Problem}

Conventional mathematics education practice was largely guided by positivistic thoughts, and behaviorist approaches of teaching-learning activities that regard mathematics assessment as an externally designed standardized tool to capture and measure an individual attributes for rating his/her educational attainment. Freeman and Lewis (2004) argued that assessment is the process of making judgment about the teachinglearning status of the students, institutions and effectiveness of the overall program for the grand purpose of improving or enhancing students' performance and providing the necessary feedbackbased oncollected

1 Mr. Lamichhane is a Lecturer of Mathematics Department of SMC, basantalamichhanne@smc.edu.np

(C) The Saptagandaki Journal. All Rights Reserved

Vol. IX

February 2018 
information through different tools and techniques. It incorporates somehow broader views of assessment as it tries to link the assessment to determine the educational status, students' performances and overall effectiveness of programme based upon the multiple source of information. It indicates that to assess students' capabilities, skills, knowledge, abilities, and concept is a very complex task. These constructs are not easily measurable and attainable because they depend on individual attributes, learning environment, socio-cultural and economic backgrounds, access of learning resources, nature of curriculum and pedagogical approaches. However, there is a general trend of assessing the students' performance based on paper-pencil tests at the end of the academic session. In my opinion, it can only measure the objectives of retaining, literal understating, procedural algorithms and skills to solve book-driven routine problems. In my understanding, the major objectives of the mathematics assessment should ensure for developing creative, imaginative and critical thinking so that learners become conscious citizen (Ernest, 2001) and would contribute for the deep democratic and socially just practices in the society, institution and nation at large. But the conventional approaches of assessment have not acknowledged these attributes.

In our general practices, assessment systems do not incorporate such types of tools, techniques and processes that can explore multifaceted abilities of learners. Traditional assessment process adopts an approach that signifies singular meaning or truth such as right or wrong, success or failure and thus creates a disempowering hierarchy (Awasthi, 2004) among students. The narrow concept of assessment seems to be integral component of dehumanizing and decontextualized curriculum, conventional pedagogical approaches and positivist philosophy of education, and absolutist views of mathematics (Luitel, 2009). Assessment system is governed and directed largely by the purposes of curriculum, which is further related to paradigms of education that determines the vision of the mathematics education. For instance, if the vision of mathematics education is to produce the creative and critical citizen, then the accompanying assessment policy focuses on authentic and performance based assessment that offer for demonstrating and performing the critical and creative works lead by constructivist notions of learning (Romberg, 1993; Lamichhane, 2017). It focuses on holistic approaches of assessment and tries to explore whether each students has developed the ability of solving non-routine problems independently that have been encountered during their academic, professional and personal lives as well. Moreover, it also devotes to assess the students from multiple perspectives: whether students are able to communicate mathematically, reason creatively, and apply mathematics for solving the varieties of problems in an emerging situation. These features of educational objectives and assessment approaches are absolutely lacking in positivistic oriented curriculum practices. Positivistic oriented curriculum practices offer behaviorist notions of teaching-learning activities that focus on imparting the certain mathematical facts, concepts, skills and knowledge to the learners. Then obviously, the process of assessment is restricted to measure those facts, skills, concepts and knowledge to determine whether the students are able to recite and reproduce these mathematical attributes (Romberg, 1993). It indicates that assessment system that is being practiced in school or university has link with the visions or paradigms of education (learning). That means the assessment system is not a separate endeavour. 
Assessment system is entirely embedded in an educational system from the very beginning of the educational process (Freeman \& Lewis, 2004). It does not provide any substantial meaning or significance in an educational arena if it is looked as an external part of educational activities. So, for the betterment of the mathematics educational practices, we have to pay our attentions towards the role of assessment in mathematics education. Keeping these views in mind, I would like to explore assessments practices of Nepal, Finland, China, and USA that reflect on students' achievement in mathematics.

\section{Statement of the Problem}

Mathematics is regarded as an extremely powerful tool for the development of other human disciplines and represents the most of the phenomenon under natural sciences more accurately and exactly (Goodwin, et al., 2014). Its features of consistency and accuracy within the certain assumptions make its roles pervasive, and rarely find any natural and social sciences where mathematics has not been applied (Goodwin, et al., 2014). However, there is a general trend to refer mathematics as the 'killer' subject (Rampal \& Subramanian, 2012) as most of the students are not able to perform well in mathematics from the very beginning of the school year. Rather than considering the overall development or viable performance of the students most of the stakeholders, social institutions and funding agencies give more priority to the marks or grades obtained by the students. As I experienced during my academic and professional years, most of the teachinglearning activities in mathematics focused on achieving the better marks in the so-called standardized final examination but the result did not support the claim.

One of the biggest problems of the mathematics education in Nepal is that a large number of children do not complete the full cycle of primary education (Wagle, 2012) and most of them fail in mathematics. The average achievement of early grade mathematics (Grade 1-3) was found to be 32 (out of 100) with standard deviation of 24 (World Education, 2013). It indicates that the mathematical achievement in early grade in the sample group was very poor and the high standard deviation of achievement signified that there is the huge gap in achievement among the students. The result seems to be somehow consistent with the national average of grade three students that was approximately 44 (out of 100) with standard deviation of 22(Educational Review Office, 2016). Similarly, the grade five students secured an average mark of 48 (out of 100) with standard deviation of 21 (ERO, 2016). It further indicated that there have been decreasing trends of mathematics achievement. Students get higher marks in lower level of cognitive domain than that of higher level of cognitive domain in both grades (ERO, 2016). Primary levels education that has been taken as the foundation for a secondary and tertiary education is very poor. The poor performance in primary level also helps to develop the negative attitudes and beliefs towards mathematics (Belbase, 2013). The poor performance, negative beliefs and attitudes prepare the grounds of creating vicious circle of negativity, disliking, avoidance, and anxiety. In this situation, there arise many questions. Why is the mathematical achievement very poor? Who is responsible for this? Are our curriculum practices, pedagogical approaches and assessment system responsible? The poor performance in mathematics has not only been the case of the Nepal. The international practices of school mathematics have also been suffering from different types of problems including low achievement. 
Highlighting the international achievement of fourth grade students in Trends in International Mathematics and Science Study (TIMSS), Mullis, Martin, Foy, and Arora, (2012) explored that out of 63 countries or regions 27 countries or regions achieved more than central scores (In TIMSS, the marks ranges 0-1000 and 500 regarded as the central point not an international average) and 26 countries secured below the central point. In this study, East-Asian countries received the highest scores but the students from these countries did not feel the confidence in mathematics. Two third of fourth grade students do not feel the confidence in their mathematical ability and nearly half of the fourth grade students like learning mathematics. The TIMSS 2011 results consistent with the Programme for International Students Assessment (PISA, 2012) in which East-Asian countries had the highest scores in mathematics and science. Out of the 64 countries and economies participated in PISA between 2003 and 2012, only 25 countries improved in mathematics performance. At the same time, 23\% students from the member countries of Organization for Economic Cooperation and Development (OECD) and 32\% students in all participating countries did not reach the baseline level 2 in PISA mathematics assessment. Moreover, the percentage of top performing students is only 13 (level 5 or 6) in which the students are able to solve the complex mathematical model and can develop the creative thinking ability (OECD, 2014). These studies indicate that there should be urgent need to consider about mathematics education programme. Those students who secure highest marks in mathematics do not feel comfortable in mathematics learning and have low self-confidence level and those who have some confidence level in mathematics do not perform well in international mathematics achievement test. For example, the East-Asian countries have secured the highest marks as compared to their western counterparts but the students from the East-Asian countries could not be able to demonstrate their self-confidence level in mathematics learning (Mullis, Martin, Foy, \& Arora, 2012). What are the reasons, factors or forces behind it? How to minimize such type of problems are some of the major concerns in present mathematics education research.

Describing some of the problems that had been inbuilt in mathematics education in general and early grade mathematic education in particular the Indian government's report on 'Learning without Burden' states that most of the students in primary level were not dropping or failing out but actually they were pushed out due to irrelevant curriculum practices and most of the contents in early grade mathematics distanced from the lives of the majority of the students (Government of India, 1993, as cited in Rampal \&Subramanian, 2012). Most of the students have regarded mathematic as one of the boring or tedious subjects as the result of an outdated teaching-learning and assessment strategies which are pervasive in school level education (Lamichhane \& Belbase, 2017). Are there any resolutions or are always remain obscure in an education milieu? It creates some confusions and tension in my mind about the assessment practices and perspectives in mathematics around the world and consequently becomes enthusiastic for exploring the assessment practices in mathematics in local and global context.

The perspectives of mathematics assessment have not changed accordingly as the paradigms shift in mathematics education. In this context, the study supplies the relevant information regarding the best 
assessment practices in mathematics which are supposed to help the educators, researchers, teachers and policy makers to incorporate best practices of assessment. Similarly, this study also creates the new discourse and avenue in the field of mathematics education research in the context of Nepal. Moreover, in my best knowledge, no study has been done in the field of assessment in mathematics with respect to international practices in our context.

\section{Procedures of the Study}

To explore the assessment practices in mathematics of the selected countries, I deployed the qualitative descriptive and explorative design. For this, I selected four countries: China, Finland, USA and Nepal purposively. The first is an emerging country for its economical, scientific and technological development and some of its provinces stood in the significant position in an international achievement tests. Similarly, USA continuously improves its position in latest versions of PISA and TIMSS and the Finland is one of the country that would be able to draw an attention of research communities as it secures the remarkable position in an international comparative assessment tests. Moreover, these three countries represent the different cultural traditions. Generally, China and USA representthe East-Asian and western cultural traditions respectively whereas Finland is from European region. For the purpose of generating and exploring the textual data, I reviewed the latest articles, policy documents, mathematics curricula freely available in different search engines. I deployed the procedures of combination of descriptions, analysis and interpretation of the textual data(Wolcott 1994, as cited in Creswell, 2012). In doing so, I read and reread the collected literatures, curricular documents, research articles several times to generate the meaning and essences of assessment practices in mathematics among the selected countries.

\section{Assessment Practices of Selected Countries}

The main objective of the study is to explore mathematics assessment practices of the selected countries. From the analysis of the textual data, I realize that the assessment system has been implementing to assess the students achievement is determined by the deep rooted thoughts or worldviews of education adopted by the authorities and nation at large. That is, the actions of the every people are the reflection of their worldviews. I capturetwo broad categories: post/positivist perspective and integral perspectives of assessment in mathematics have been practicing in the selected countries. Now, I would like to describe some key features, attributes, aims and procedures of assessment system under these paradigms.

\section{Post/Positivistic Perspective of Assessment}

Assessment system is not an isolated educational entity, itis largely embodied inwhole education system. What types of assessment should be implemented to assess the student outcomes link to the paradigms of education in general and mathematics education in particular. Different countries have set their educational priorities according to their needs, market demands, development of scienceand technology,economic status and socio-culturalaspectsetc.in particular and their worldviews or paradigms of mathematics education in general. Every countries have their long historical and cultural traditions that explicitly or implicitly arereflected on education system. 
Chinese mathematics education practices have been guided by the Confucian tradition that has somehow similar attributes positivist paradigm. The Confucius tradition acknowledged for developing the two basic skills among the pupils (Tu\& Shen, 2010). It further incorporated the controlling and managing strategies in which students are urged to learn what teachers or authorities considered as significant for their future life(Tu\& Shen, 2010). This tradition of mathematics education focuses on imparting knowledge, concepts, facts and skills to the students. Teachers and text books have been regarded as the ultimate sources of knowledge in which teachersare supposed to transmit their mathematical knowledge and concept among the pupils. When the aims of mathematics education and teaching-learning activities focus on developing the universal objective knowledge through transmissionist approach then obviously assessment system is limited to measure a so-called universal mathematical knowledge. It incorporates only standardized paper-pencil test for measuring and determining the students' attainments of the mathematical outcomes. The unidimensional nature of paper-pencil test has not been able to measure the overall development of students. The declarative assertions of questions offer objectives solutions in closed form. It does not flourish the grounds for developing creative, critical and imaginative thinking. Similarly, its time bounded naturelargely limits to assess the memorizing power of students, algorithmic skills to solve routine problems and mechanistic approaches of proving theorems. Such conventional approaches of assessment system largely focus on measuring the lower level cognitive objectives: remembering, understanding, applying and analyzing. It is not exaggeration to say that the assessment system that is being practiced since the very beginning of the formal educational system has an adverse affect on mathematics education. In my experiences, most of the classroom activities devote to imparting above stated mathematical objectives. Due to prolong engagement in such types of practices, teachers and students are already de-skilled (Grundy,1987) and thus unable to pay attention for developing creative and critical thinking.From the above discourse, I realized that the Chinese assessment systems highly rely on positivistic approaches of assessment which depend on externally imposed examination.

The examination is a great feature of Chinese education system. It is a part of a typical Chinese traditional culture. There are many exams at different stages of semesters, e.g., monthly exams, unit tests, mid-semester exam, and final exams. Examining the "two-basics" is the focal point of all the tests; this attracts more attention to the "two-basics" teaching (Tu \& Shen, 2010). This shows that in Chinese mathematics classroom practices teachers continuously measure students' mathematical performances through the examination and provides the necessary feedbacks to the students. Though the conventional examination system has many negative effects, it also seems to play a positive leading role for increasing the marks on external national and international tests, but the level of confidence, interest in learning and self-efficacy believes on mathematics have not improve as compare to the international counter parts. In this context, there arises a serious question: whether the aims of mathematics education is to solve the routine problem or prepare a conscious citizen who might contribute the countries for the deep democratic and socially just practices in immediate socio-cultural milieu and nation at large. The post/positivist oriented features of mathematics education and assessment systemis pervasive not only in east-Asian countriesbutalso in western countries. The overarching goal of mathematics education in United States of America (USA) was to prepare students 
to function as productive citizens in a highly industrialized and technical society (Wnag \& Lin, 2009). It indicates that US mathematics education practices focus on utilitarian values of mathematics. The utilitarian views of mathematics offer the mechanistic, linear and reductionist model of teaching-learning activities and assessment system in which students are urged to solve the mathematical problems that are highly relevant to industrialized global markets. They view mathematics as pure and universal knowledge, and educational institutions intend to impart this knowledge into their pupils so that they can easily be sellable into markets. Such dehumanizing views of mathematics that does not recognize the learners as cognizing being and largely emphasize on technicality of mathematics. That is, US mathematics education practices recognize mathematics as one of the most important tools for controlling and managing of natural, human, social and cultural phenomenafor profit making.Besides these, US mathematics education practices give higher priority for the individual interest for particular subject matters within their rigid standardized framework (Wang \& Lin, 2009). They do not give more pressure for students to learn much mathematical contents and solve more mathematical problems from different textbooks whereas Chinese mathematics education practices focus on learning more and more mathematical contents and do much drills or practices for being success on mathematics and also puts pressure on their students to perform best in mathematics achievement. Such mathematical activities demand the positivist approaches of assessment.

The most important aspect of positivist oriented assessment approaches is that it regards teaching-learning activities and assessment system as an isolated endeavour. It views knowledge as 'out there' and already exist somewhere in the world. The works of the teachers divulge the knowledge as it exists into the mind of the students and thus assessment tends to measures whether the students are able to recite or reproduce the knowledge or not. It indicates that mathematics education practices of these two countries seem somehow different but the major essence of assessment system in mathematics tends to measure students' achievement quantitatively for upgrading the students by the help of conventional time bound standardized paper-pencil test.

The US assessment practices of mathematics largely focus on the standard test. Students may take standardized tests such as the Scholastic Assessment Test (SAT) or the American College Test (ACT) for getting admission to university, although not all institutions rely upon these examinations (Dossey, Halvorsen, \& McCrone, 2012). Teacher made assessments are taken into consideration to determine performance in upper secondary school (high school) completion. Approximately 40 states have declared minimum competency criteria for all public school students and specified subgroups (Dossey, Halvorsen, \& McCrone, 2012). Moreover, the 'No Child Left Behind' (NCLB) Act of 2001 also recommends that every states should measure student progress in reading and mathematics in years 3 through 8 and at least once during years 10 through 12 (Dossey, Halvorsen, \& McCrone, 2012). It highlights that US education system largely acknowledges the standardized mathematics test in different years of schools and university as well. They only focused on quantitative aspect of assessment. In this perspective, the function of assessment is largely ranking and grading the students on the basis of the marks obtained in the examination. 
The summative function of assessment has largely taken assessment as an external entity that has deployed at the end of academic session for determining the ranks of the students. It indicates that the summativeassessment measures the factual mathematical knowledge that has acquired during the classroom teaching-learning activities. The acquired so-called marks or grades are used to create disempowering hierarchy among the practitioners', leads to the socially unjust practices within the classroom in which most of the moderate or low level intelligent students feel disempowered which is one of the forms of a symbolic violence in mathematics classroom (Bourdieu, 1991; Lamichhane \& Belbase, 2017). Thus, the purpose of assessment of learning simply measures the non measurable attributes of the individual ability, capacity and compare with certain norms without consideration of other factors that heavily influence mathematics achievement. Most of the assessment practices have been influenced by psychological and curriculum reform traditions aimed to search for reliability, in the sense of accuracy of measurement, and curricular and content validity (Morgan, 2000). That is, it haseasily seen the impact of the mid $20^{\text {th }}$ centcury mathematical reform movement in western countries, such as 'New Math' and Bourbaki groups, on assessment in mathematics education that focus on the mastery of learning mathematical facts, rules, concepts, theorems etc. heavily rely on deductive reasoning (Clements \& Ellerton, 1996). It shows that from the very beginning of the formal mathematics education practices, the assessment system of mathematics education based on paper-pencil tests to explore the mastery of students learning.

Assessment of learning aims to categorize the achievement of the learners at the end of certain period of times (e.g. end of an academic session, end of learning unit). The focus is to explore how much students have learned. Assessment oflearning is used not only to ascertain the present level of achievement, but also to provide an external frame of reference on that achievement, and ranks the students on the basis of an externally pre-specified norm. It has been used in mathematics education practices since the early stage of the formal schooling. For thousands of years, Chinese mathematics education has used examinations as a means to determine their future career (Tu\& Shen, 2010) which is culturally valued. The assessment practices at schools are often teacher-led with a strong emphasis on demonstrating factual knowledge. Such type of assessment practices blended with narrowly conceived teaching lead student to rote-memorization and restrained students from achieving their full potentiality.Such features of post/positivist approaches of assessment in mathematics can be observed in Nepali mathematics education practices.

Nepali mathematics practices adopt the positivistic approaches of assessment since the era of modern history of mathematics. Most of curricular documents (CDC, 2015; 2008, 2007) focus on standardized mathematics assessment for upgrading the students. The assessment system largely depends on marks obtained by the students in time bounded paper-pencil test at the end of the academic year. Generally, assessments in mathematics call for reproducing the discrete mathematical facts, formulae and theorems that have been taught/ learned throughout the academic year. In school years students should take four standardized tests at the end of 8, 10, 11 and 12 years. The major functions of these tests are to determine the achievements of students and upgrading them for next level of schooling. Such externally imposed standardized paper-pencil 
tests are rarely able to incorporate other aspects of teaching-learning mathematics such as socio-cultural background, economic status, assess to educational resources, individual traits; beliefs, perceptions, attitudes, emotions etc. have played significant roles in teaching-learning activity and assessment in mathematics at large. It provides the little opportunity for student to engage in learning activities that might deter the creative and analytic thinking and ability of the learners. It almost ignores how students learn and how to energize, encourage, and promote the students to learn mathematics independently.

In this regards, I realize that our long-rooted positivist oriented assessment system in mathematics pushes mathematics education practices towards the transmissionist ways of teaching-learning activities in which most of the activities devote to reproduce the discrete subject matters. Nepali mathematics practices and assessment system unduly fall into the vicious circle of positivistic thought in which the students had been penalized for giving creative answers in their School Leaving Certificate (SLC) exam (Mathema \& Bista, 2006). Such reductionist approaches of teaching-learning and assessment system might be the reflection of absolutist philosophy of mathematics in which mathematical objects are regarded as 'out there' (Ernest, 1991; Luitel,2013) and thus teachers and students engage in drills and practices until and unless they can bring these objects in their real field. Such dehumanizing and decontextualized mathematics education practices are deterrent to Nepali mathematics education, and also flourish the grounds for blaming culture in which no one is ready totake the sole responsibility of educational activities that have been taken place in schools and university at large (Luitel, 2009). The conventional assessment system of Nepali mathematics education practices rarely have incorporated the newly emerging feature of assessment so that we can improve the whole mathematics education programme by using the information exploring through the assessment tools.National Curriculum Framework for School Education in Nepal (Ministry of Education, 2007) somehow realized the role of multi-perspectival assessment system in which the information exploring from the assessments have not only used for measuring the students achievement but alsoused for redefining, reshaping and restructuring the exiting mathematics program at large.

From this discourse, I conclude that the post/positivistic approaches of assessment system rarely incorporate the humanitarian, psychological, affective, socio-cultural, and political aspects of mathematics and its learning. These components inbuilt in mathematics education practices and thus have significant role in teaching-learning activities and assessment system at large. Many researchers, philosophers, mathematics educators and curriculum experts (Cobb, 2006; Luitel 2009; Malloy \& Malloy, 1998; Skovsmose \& Valero, 2001) largely acknowledge the role of these components in mathematics education practices.

\section{Integral Perspective of Assessment}

Finland has own contextual mathematics education practices and alternative approaches of assessment. The Finnish mathematics education aims to improve student skills and orient to change the students' perspectives on mathematics. The mathematical skills that Finland wants to enhance are somehow different from the general conceptions of skills. The mathematics skills include communication (both oral and 
written) skills, problem solving skills and calculation skills help to enhance the conceptual and relational understanding (Mendaglio, 2014). To achieve these goals, Finnish mathematics teachersdeploy the inquiry based teaching strategies so that students enable to make a conjecture, estimate or forecast the future events and find a creative solutions that help to acclimatize students to mathematical way of thinking. It indicates that Finnish mathematics education adopt the emerging trends of mathematics education. The Finnish mathematics education practice does not have a centralized curriculum and assessment system in school education. There is a broad national framework of curriculum. Teachers or school authorities have a right to design the curriculum according to their local context, needs and immediate environment. To maintain the rationale balance between teaching-learning activities and assessment system the Finnish education practices incorporates multiple ways of assessing the students' performance or outcomes.

The Finnish school level curriculum highlights that assessment is inbuilt in teaching-learning activities. Students are assessed by multiple ways via demonstration, project works, collaborative works, class performances, observations, portfolio and peer assessment. Such emerging or flexible approaches of assessment systems acknowledge the individual differences in learning, socio-cultural and political aspects of learning, economic background and access in educational opportunities. Such a holistic approach of assessing the students' performances in mathematics help to develop the positive attitude towards mathematics and consequently increase the level of confidence in mathematics learning and self-efficacy believes that are more viable components for the betterment of the mathematics education. In this perspective, assessment is taken as formative process of learning.

The Finnish assessment practices focus on ongoing learning process rather than external evaluation. After implementing the new approaches of assessment in 2010 (Finnish National Board of Education, 2010, as cited in Hendrickson, 2011), students take national standardized test at the end of basic education but the test score has not used to rank the students.It is used to determine the effectiveness of national curriculum and other policies of education. Every schools prepare their self-assessment reports yearly and make it public to communicate its educational standard to a wider community. That is, schools and teachers are not evaluated only on the basis of students' achievement scores. They give more emphasis to an attainment of educational outcomes of schools should be consistent with national curricular outcomes (Hendrickson, 2011). That is,national monitoring and evaluation process focus on the extent to which schools have metthe objectives set in statutes, education policies, and in the core curricula. It indicates that the Finnish approaches of assessing the student performance tilt towards socio-cultural perspective of assessment (Conway \& Sloane, 2005).

In my understanding, socio-cultural perspectives do not try to assess the isolated discrete concepts in mathematics. It focuses on exploring the holistic development of students. It prefers collaborative works of the learners so that they develop the mathematical model represents different socio-cultural and real-world problems. The socio-cultural perspective of assessment considers the students' socio-cultural background, 
economic status, access of learning resources, and languages used in school and at home while assessing the students' performance in mathematics (Malloy \& Malloy, 1998). That is, the Finnish education system acknowledges assessment as an integral part of mathematical activities in classroom always focuses on formative aspect of learning.

The aim of formative assessment is to encourage pupils to learn mathematics on their own pace, provide the immediate feedbacks that facilitate students learning, and help to develop the positive attitudes towards the mathematics. To assist students in which they feel some discomfort in learning mathematics,diverse assessments tools: journal writing, assessment interviews, oral assessment,observations and portfolio assessments are used for the diagnosis of learning status of the students for the purpose of enriching teachinglearning activities rather than ranking the students' position. The Finnish National Board of Education issues national criteria for teachers to assess the students' performances.Similarly, national curriculum framework outlines the principles of student assessment that include self-assessment skills and developinga habit of independent learning so that they become the creative and imaginative thinkers (Hendrickson, 2011). Besides these function of assessment, the purpose of assessment in this approach is quite different from the post/positivist approaches of assessment.

During the passage of time, the advancement of learning theories incorporate the social and individual aspects of learners that floated so many newly emerging concepts in mathematics learning arena impact the assessment approaches as well. From the analysis of the documents, I have captured two purposes of assessment under an integral perspective: assessment for learning and assessment as learning.

Assessment for learning is all about informing learners of their progress to empower them to take a necessary action to improve their performance. Teachers need to create learning opportunities where learners can progress at their own pace and undertake consolidation activities where necessary. Hendrickson (2011) examined the Finnish assessment system and found that there is a provision of normative assessment for finding students present learning status that helps to provide the necessary feedbacks.As opposed to the general convention of education for competition that ranks the students on the basis of their marks on achievement test, Finnish national curriculum rely on the principles of collaborative and cooperative learning (Kasanen, Raty, \& Snellman, 2003, as cited in Hendrickson, 2011). It showed that assessment has used to cultivate students' active learning skills by asking open-ended questions also helped students to address these problems. In this perspective, the main purpose of the assessment is to explore the present teaching-learning status and use to revise or reform the mathematical activities according to the needs and aspiration of learners. Moreover, assessment system should be able to develop the self-managing and self-monitoring aspect of learning.

Assessment as learning involves the developing metacognitive ability in students including self-monitoring of learning progress, self and peer assessment of achievement, self-motivation and self-regulation, and sets their learning activities accordingly (Earl \& Katz, 2006). It means that to cultivate the ability to engagein 
independent learning through critical self-reflectivepractices is the major function or purpose of assessment in mathematics education. The main purpose of assessing students is to guide and encourage students' own reflection and self-assessment (Hendrickson, 2011). The Finnish mathematics classroom accompanies with the assessment system in which students are generally engaged in independent learning activities and often set their won targets with the help of teachers for fostering analytical and problem solving skills (Sahlberg, 2007).Realizing the importance of alternative approaches of assessment in education, Chinese ministry of education recently incorporates the policy of assessment as learning and assessment for learning for the betterment of teaching-learning activities in mathematics (Wang \& Lin, 2009). Similarly, the role of alternative approaches of assessment has been realized by Nepali schools in general and mathematics education programme in particular.

Primary school curriculum of Nepal (Curriculum Development Center, 2007) introduced the concepts of Continuous Assessment System (CAS) and liberal promotion policy in 1-3 years of schooling. It gradually extends to foundation level (up to 8 years of schooling). The impact of CAS and liberal promotion policy do not sound good. The average achievement of class threes students in 2011 is decreasing than that of 2008 (ERO, 2012). The trends have not significantly changed till now. Why is such situation arises the serious question for the researchers and mathematics educators? It reveals that good policies and curriculum alone is not able to produce the good results or performances. In this regards, I came to conclude that the implementation of curriculum in an appropriate manner by allocating the sound human resources has crucial roles for bringing the desired results. No single reason or factor is responsible for the betterment of mathematics education. We need to balance a fine tune among the different components of educational milieu. Among these components assessment practices have crucial rule for the betterment of the mathematics education. By actualizing the positive impact of alternative perspective of mathematics assessment, most of the countries seem to orient toward alternative approaches of assessment.

\section{Discussion and Implications}

Assessment practices in school mathematics have crucial role in mathematics education. Due to irrelevant practices of assessment practices in schools' mathematics education, most of the primary students have mathematics anxiety(Wigfield \& Meece, 1988). Most of the countries around the worldhave standardized oriented traditions in mathematics education whichgave the extra burden to the students and urged to memorize mathematical facts, concepts, and algorithmic procedures for the name of achieving the better marks on that exam.

Generally, Nepal, USA and China accept the assessment as an external tool for measuring the student mathematics achievement in more uniform ways. In the history of education, such practice trace back to the Zhou dynasty in China (1207-1771 BC) which was used to select officials for the imperial civil service (Berry \& Adamson, 2011). For centuries, paper-pencil examinations have been used at schools, universities, and civil services as the fundamental assessment tools for the purpose of making judgement about their educational attainment and selection of more competent human resources for the public administration. Historical and cultural trends have been reflecting in the Chinese mathematics education system in which 
Assessment Practices in Mathematics: Local to Global Contexts

external assessment system (summative) plays a vital role for assessing the students' performances. The major tools of assessing the students' educational achievement are school work-based assessment: routine assessment, period assessment and concluding assessment and selection-aimed promotion assessments (Tu, 2009). Most of the tools are common in mathematics education practices of Nepal. However, USA and Finland do not want to give extra burden to their students for the name of examination. All of these assessments mainly focus on assessing students' mathematical knowledge, skills, and concepts that have been taught/learned during their academic session for the purpose of ranking or upgrading the students largely guided by behaviourist perspective of assessment. From the behavioural perspectives, assessment is regarded as a tool of measuring the students' performance based on reciting or remembering mathematical facts, knowledge, skills, concepts, procedures, and routine algorithms (Conway \& Sloane, 2005).

In this context, this study explains the alternative purposes of the assessment: assessment as learning and assessment for learning. If we become able to pay our attention of these purposes of assessment, we are able to discard the unhelpful aspect of traditional or conventional approaches of assessment that discriminate or ranked the students. It creates the a havoc in mathematics education practices and most of the students discard the mathematics as their future career subjects due to the fear of being unsuccessful in mathematics. In such situation, the study suggeststhat we need to introduce the alternative ways of assessment in mathematics teaching-learning activities that helpstudents and teachers to find out their educational status and set the teaching-learning activities accordingly. To shift the conventional mathematics education towards more inclusive and authentic in which students get an opportunity to learn mathematics without burden conventional assessments practice need to be changed than flourishing the grounds foroverall development of students and institutions.

Finally, I internalize that most of the authorities or mathematics educators of US, Nepal and China believe that cognition is bounded within human mind and learning as ultra-rationale and intuitional activities detach from the human socio-cultural perspectives and consequently give more emphasison standard mathematical assessment for producing more reliable and consistent results (Luitel, 2009). In contrast, Finnish mathematics educators and practitioners regard learning as one of the social process and believe that cognition is socially distributed (Cobb, 2006; Lerman, 1999) and thus incorporates the integral perspectives of assessment in which all institutional activities are assessed for the betterment of the mathematics practices.

\section{Conclusions}

In this study, I have captured the two broad approaches in mathematics assessment practices among the selected countries: post/positivist and integral perspectives. China, Nepal and USA largely acknowledge the post/positivist approaches of assessment whereas Finland adopts the integral perspectives. The Chinese and Nepali mathematics assessment practices blended with the summative approaches of assessment track back to the Confucius period and have deep rooted cultural beliefs and practices that mathematical achievement of students can be measured properly by a paper pencil standardized test. However, USA tries to maintain rationale balances between summative and formative assessment. Similarly, assessment 
of learning is the major purpose of the mathematics assessment in Chinese and Nepali schools whereas USA tries to incorporate assessment for learning as well.In contrast to these three countries, the Finnish assessment practices focus on the formative assessment. The Finnish mathematics educators, teachers, and policy makers believed that the external examination gave an extra burden to the students and create the unnecessary pressure on students that has adverse effect on mathematics education. Assessment as/for learning is the major purpose of learning in Finnish schools. It indicates that Finnish mathematics education practices want to develop the creative and metacognitive thinking to their students rather than imparting the mathematical knowledge, concepts and skills so that they become potential and consciouscitizen fully participate in societal activities.

\section{References}

Awasthi, L. D. (2004). Exploring the monolingual school practices in multilingual Nepal. Unpublished doctoral dissertation, Danish University of Education, Copenhagen, Denmark.

Belbase, S. (2013). Images, anxieties, and attitude toward mathematics. International Journal of Education, Mathematics, Science and Technology, 1(4), 230-237.

Berry, R., \& Adamson, B. (2011). Assessment reform past, present and future. In Rita, B. \& Bod, A. (Eds.). Assessment reform in education: Policy and practice. London, New York: Springer

Bourdieu, P. (1991). Language and symbolic power. (Raymond, G, \& Adamson, M. Trans.). Uk: Polity Press.

Clements, M. A., \&Ellerton, N. F. (1996). Mathematics education research: Past, present and future. Thailand: UNESCO Principal Regional Office for Asia and the Pacific.

Cobb, P. (2006). Mathematics learning as social practices. In J. Maasz \& W. Schloeglmann (Eds.).New mathematics education research and practice. Rotterdam/Taipei: Sense Publishers

Conway, P. F. \& Sloane, F. C. (2005). International trends in post-primary mathematics education. National Council of Curriculum and Assessment.

Creswell, J. W. (2012). Educational research: planning, conducting and evaluating quantitative and qualitative research ( ${ }^{\text {th }}$ ed.). Boston: Pearson.

Curriculum Development Centre. (2007). Primary school curriculum. Bhaktapur: Author.

Curriculum Development Centre. (2008). Secondary School curriculum: Compulsory Subjects. Bhaktapur: Author

Curriculum Development Centre. (2015). Secondary School Curriculum, Class 9-10 (Compulsory Subjects). Bhaktapur: Author.

Dossey, J. A., Halvorsen, K. T., \& McCrone, S. S. (2012). Mathematics education in the Unites States 2012: A capsule summary fact book. USA: National Council of Teachers of Mathematics.

Earl, L. \& Katz, S. (2006). Rethinking classroom assessment with purpose in mind: Assessment for learning, assessment as learning, assessment of learning. Canada: Maintoba Education.

Education Review Office. (2011). National assessment of student achievement [NASA]. Bhaktapur: Author. Educational Review Office. (2016). National assessment of student achievement [NASA]. Bhaktpur: Author. Ernest, P. (1991). The Philosophy of Mathematics Education. UK: Routledge Falmer. 
Assessment Practices in Mathematics: Local to Global Contexts

Ernest, P. (2001). Critical mathematics education. In Gates, P. (Ed). Issue in mathematics teaching. New York: Routledge Falmer.

Freeman, R. \& Lewis, R. (2004). Planning and implementing assessment .London, New York: Routledge Flamer.

Goodwin, D., Bowman, R., Wease, K., Keys, J., Fullwood, J., \& Mowery, K. (2014). Exploring the relationship between teachers' images of mathematics and their mathematics history knowledge. Philosophy of Mathematics Education Journal, 28.

Grundy, S. (1987). Curriculum: Product or praxis. London: The Flamer Press.

Hendrickson, K. A. (2011).Assessment in Finland: A scholarly reflection on one country's use of formative, summative, and evaluative practices.Mid-Western Educational Researcher 25, (1/2).

Kelly, D., Xie, H., Nord, C. W., Jenkins, F., Chan, J. Y., \& Kastberg, D. (2013). Performance of U.S. 15-year-old students in mathematics, science, and reading literacy in an international context: First look at PISA 2012 (NCES 2014-024). U.S. Department of Education. Washington, DC: National Center for Education Statistics.

Lamichhane, B. R. \& Belbase, S. (2017). Images of mathematics held by undergraduate student. International Journal on Emerging Mathematics Education, 1(2), 147-168. http://dx.doi.org/10.12928/ijme.

Lamichhane, B. R. (2017). Teachers' beliefs about mathematics and instructional practices. The Saptagandaki Journal, III. Bharatpur: Research Management Cell, Saptagandaki Multiple Campus.

Lerman, S. (1999). Culturally situated knowledge and the problem of transfer in the learning of mathematics.

In L. Burton (Ed.).Learning mathematics: From hierarchies to networks (pp. 93-107). New York, NY: Falmer.

Luitel, B. C. (2013). Mathematics as an im/pure knowledge system: symbiosis, (W)holism and synergy in mathematics education. International Journal of Science and Mathematics Education, 10 (6). Taiwan: Springer ISSN 1571-0068. doi: http://dx.doi.org/10.1007/s10763-012-9366-

Luitel, B.C. (2009).Culture, worldview and transformative philosophy of mathematics education in Nepal: A cultural-philosophical inquiry. Doctoral dissertation, Curtin University of Technology.

Malloy, C. E. \& Malloy, W. W. (1998). Issues of culture in mathematics teaching and learning. The Urban Review, 30 (3), 245-257.

Marshman, M. \& Grootenboer, P. (2012). Scissors, Papers Rock: Old-World Technologies for FutureProofing Pedagogy. Re-engaging Students in Mathematics Classrooms. In Rowan, L. \& Bigum, C. (Eds.). Transformative Approaches to New Technologies and Student Diversity in Futures Oriented Classrooms: Future Proofing Education. (pp. 139-158). Australia: Springer Science + Business Media B. V.

Mathema, K. B. \& Bista, M. B. (2006). Study on Student Performance in SLC (Main Report). Kathmandu: Ministry of Education and Sport, Education Sector Advisory Team.

Mendaglio, A. (2014). A Comparative Review of Mathematics Educational Strategies in Ontario and Finland. Fields Mathematics Education Journal, 2, 2-24.

Ministry of Education. (2007). National curriculum framework for school education in Nepal. Kathmandu: Author. 
Morgan, C. (2000). Better assessment in mathematics education? A social perspective. In J. Boaler (Ed.). Multiple perspectives on mathematics teaching and learning. London: Abelx publishing.

Mullis, I., Martin, M. O., Foy, P., \& Arora, A. (2012). TIMSS International results in Mathematics. Boston, MN: TIMSS and PIRLS International Study Center.

OECD (2012). United State-Country Note: Result form PISA 2012: Author

OECD (2014). PISA 2012 results in focus: What 15-year-olds know and what they can do with what they know. Author

Rampal, A. \& Subramanian, J. (2012). Transforming the elementary mathematics curriculum: Issues and challenges. In R. Ramanujam \& K. Subramaniam (Eds.). Mathematics education in India: Status and Outlook. Mumbai: Homi Bhabha Center for Science Education, Tata Institute of Fundamental Research.

Romberg, M. A. (1993). How one comes to know: Models and theories of the learning of mathematics. In M. Niss (Ed.). Investigations into assessment in mathematics education: An ICMI study. Dordrecht/Boston/London: Kluwer Academic Publishers.

Sahlberg, P. (2007). Education policies for raising student learning: the Finnish approach. Journal of Education policy, 22 (2), 147-171.

Skovsmose, O. \& Valero, P. (2001). Breaking political neutrality: The critical engagement of mathematics education with democracy. In B. Atweh; H. Forgasz; \& B. Nebres (Eds.). Sociocultural research on mathematics education: An international perspective. Mahwah/ New Jersey/ London: Lawrence Erlbaum Associates, publishers.

Tu, R. \& Shen, W. (2010). Fundamental focuses of Chinese mathematics education: Characteristics of mathematics teaching in China. Journal of Mathematics Education, 3 (2), 160-169.

Tu, R. (2009). Assessment of mathematics education in China. Journal of Mathematics Education, 2 (1), 115-120.

Wagle, D. (2012). Dropout of children from schools in Nepal. M.Phil. dissertation, Norwegian University of Science and Technology. Norway.

Wang, J. \& Lin, E. (2009). A meta-analysis of comparative studies on Chinese and US students' mathematics performance: Implications for mathematics education reform and research. Educational Research Review, 4, 177-197.

Wigfield, A., \& Meece, J. (1988). Math anxiety in elementary and secondary school students. Journal of Educational Psychology, 80(2), 210-216.

World Education (2013). Learning status of our children: Challenges and opportunities. Kathmandu: Author. 